\title{
Influence of binder metal and surface treatment on the corrosion resistance of $(\mathrm{W}, \mathrm{Ti}) \mathrm{C}$-based hardmetals
}

\author{
C.F. Barbatti ${ }^{a, *}$, F. Sket ${ }^{a, 1}$, J. Garcia ${ }^{b}$, A. Pyzalla ${ }^{a, 1}$ \\ ${ }^{a}$ Institute of Material Science and Technology, TU Wien, 1040 Vienna, Austria \\ ${ }^{\mathrm{b}} \mathrm{R} \& \mathrm{D}$ Boehlerit GmbH and Co.KG, 8605 Kapfenberg, Austria
}

Received 13 March 2006; accepted in revised form 3 July 2006

Available online 14 August 2006

\begin{abstract}
The effect of a nitridation surface treatment on the microstructure and corrosion resistance of Co and Ni-binder (W,Ti)C-based hardmetals with additions of $(\mathrm{Ta}, \mathrm{Nb}) \mathrm{C}$ was investigated. Nitridation treatment produces a surface layer with a higher hard phase $(\mathrm{Ti}, \mathrm{Ta}, \mathrm{Nb}, \mathrm{W})(\mathrm{C}, \mathrm{N}) \mathrm{content}$. The near-surface layer thickness and microstructure are affected by the choice of binder (Co respectively Ni). The corrosion resistance of the hardmetals was characterized using linear sweep voltammetry. The microstructure of the hardmetals was determined before and after corrosive attack by optical microscopy and SEM. The results of the corrosion tests and microstructure analyses are interpreted in terms of the correlation between the hardmetal morphology and porosity and ion transport through the interface binder-electrolyte. The nitridation treatment of the hardmetals strongly increases the resistance to aggressive corrosion media for hardmetals both with Co and Ni-binder phase and thus may positively influence the hardmetal lifetime in cutting applications in chemically aggressive environments.
\end{abstract}

(C) 2006 Elsevier B.V. All rights reserved.

PACS: 81.05.Mh; 81.65.-b; 81.65.Lp; 82.45.Bb

Keywords: Hardmetals; Binder phase; Nitridation; Corrosion

\section{Introduction}

Hardmetals are composite materials, which consist of hard refractory carbides containing metals of the transition groups IV, $\mathrm{V}$ and $\mathrm{VI}$ (such as $\mathrm{WC}, \mathrm{TiC}, \mathrm{TaC}, \mathrm{NbC}$ ) embedded in a tough metal binder phase. Cobalt is by far the dominating binder metal employed due to its excellent wetting to $\mathrm{WC}$ and its good thermo-mechanical properties [1-3]. Hardmetals are commonly applied as tools for machining of ferrous alloys, but also for machining non-ferrous alloys, wooden parts, or rocks. The performance and lifetime of the cutting tools depend on the mechanical, structural, and chemical-physical properties of the hardmetals as well as on the operation conditions and the cha-

\footnotetext{
* Corresponding author. Now at: Max-Planck-Institute for Iron Research, 40237 Düsseldorf, Germany. Tel.: +49 2116792 210; fax: +49 2116792390 .

E-mail address: c.barbatti@mpie.de (C.F. Barbatti).

${ }^{1}$ Now at: Max-Planck-Institute for Iron Research, 40237 Düsseldorf, Germany.
}

racteristics of the environment in which they are employed. It is particularly challenging to produce hardmetals that are resistant to oxidative environments. Aggressive oxidative environments are found for instance in the machining of green wooden parts $[4,5]$. Pugsley et al. [4] have shown that machining of wood with high moisture content leads to a rapid degradation of the hardmetal. The combination of the non-homogeneous multicomponent hardmetal cutting tool with water and the soluble substances in wood provides propitious conditions for electrochemical action [6].

Since the binder phase is the most vulnerable component of a sintered hardmetal, much effort has been devoted to studying the interdiffusion processes that occur between the carbides and the binder phase [7-10] and their influence on the corrosion resistance of the binder phase and the hardmetals in aggressive media [7,11-13]. Corrosion of hardmetals in neutral and acidic media usually leads to a preferential dissolution of the binder phase leaving a skeleton of carbides $[6,14,15]$. This skeleton then can easily be shattered by mechanical action, since it no longer possesses a compact form [14]. 
Table 1

Composition and sintering conditions of the samples

\begin{tabular}{llll}
\hline Sample & Approximate composition (wt.\%) & Binder & Treatment \\
\hline A & $60 \mathrm{WC}-30(\mathrm{Ti}, \mathrm{Ta}, \mathrm{Nb}) \mathrm{C}-10 \mathrm{Co}$ & $\mathrm{Co}$ & - \\
B & $60 \mathrm{WC}-30(\mathrm{Ti}, \mathrm{Ta}, \mathrm{Nb}) \mathrm{C}-10 \mathrm{Co}$ & $\mathrm{Co}$ & $\mathrm{N}_{2}$ \\
C & $60 \mathrm{WC}-30(\mathrm{Ti}, \mathrm{Ta}, \mathrm{Nb}) \mathrm{C}-10 \mathrm{Ni}$ & $\mathrm{Ni}$ & - \\
D & $60 \mathrm{WC}-30(\mathrm{Ti}, \mathrm{Ta}, \mathrm{Nb}) \mathrm{C}-10 \mathrm{Ni}$ & $\mathrm{Ni}$ & $\mathrm{N}_{2}$ \\
\hline
\end{tabular}

Because the corrosion resistance of $\mathrm{Ni}$ is higher than that of Co many efforts have been carried out to produce WC-Nibased hardmetals. In some cases substituting the Co-binder phase by other alloys (e.g. Ni- or Fe-based alloys) enhanced the
Table 2

Metallographic values of volume fraction $\left(f_{i}\right)$ of all phases, average grain size of the hard phases $\left(d_{\mathrm{WC}}\right.$ and $\left.d_{\mathrm{TiC}}\right)$, and binder mean free path $(\lambda)$ in the bulk determined by image analysis

\begin{tabular}{lllllcl}
\hline Sample & $f_{\text {binder }}$ & $f_{\mathrm{WC}}$ & $f_{\mathrm{TiC}}$ & $d_{\mathrm{WC}}(\mu \mathrm{m})$ & $d_{\mathrm{TiC}}(\mu \mathrm{m})$ & $\lambda(\mu \mathrm{m})$ \\
\hline A & $0.13 \pm 0.01$ & $0.19 \pm 0.02$ & $0.62 \pm 0.04$ & $1.5 \pm 0.7$ & $3 \pm 2$ & $1.1 \pm 0.9$ \\
$\mathrm{~B}$ & $0.12 \pm 0.01$ & $0.17 \pm 0.01$ & $0.63 \pm 0.01$ & $1.4 \pm 0.7$ & $2.6 \pm 0.9$ & $1.4 \pm 1.1$ \\
$\mathrm{C}$ & $0.10 \pm 0.01$ & $0.18 \pm 0.01$ & $0.65 \pm 0.03$ & $1.3 \pm 0.6$ & $3 \pm 1$ & $1.2 \pm 1$ \\
$\mathrm{D}$ & $0.12 \pm 0.01$ & $0.17 \pm 0.01$ & $0.63 \pm 0.03$ & $1.4 \pm 0.7$ & $3 \pm 1$ & $1.4 \pm 1.1$
\end{tabular}

corrosion resistance in aggressive acidic aqueous environments $[3,11-13,16,17]$. However, a drawback of hardmetals with a Ni-
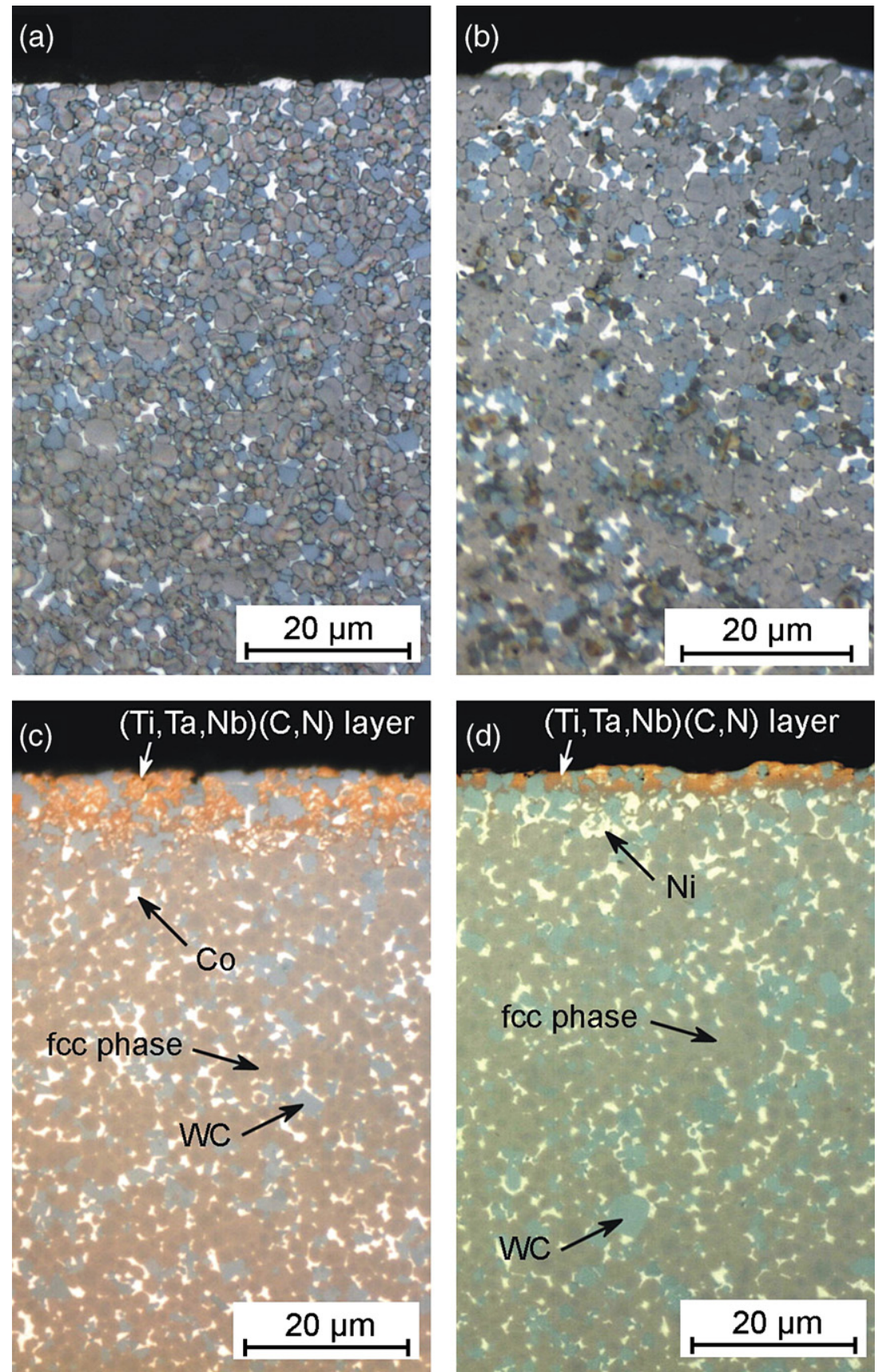

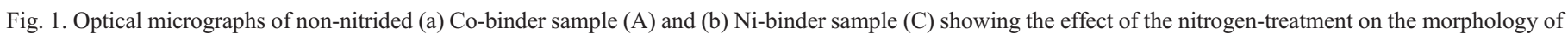
the (c) Co-binder sample (B) and (d) the Ni-binder sample (D). The white arrows indicate the fcc-rich layer. 
Table 3

Surface roughness $\left(R_{\mathrm{a}}\right)$ values of the investigated materials

\begin{tabular}{lc}
\hline Sample & $R_{\mathrm{a}}(\mu \mathrm{m})$ \\
\hline A & $1.2 \pm 0.2$ \\
B & $0.59 \pm 0.05$ \\
C & $0.59 \pm 0.05$ \\
D & $1.4 \pm 0.2$
\end{tabular}

based alloy as the binder is the lower mechanical resistance of the Ni-based alloy compared to a Co-based alloy. Another approach to improve the corrosion resistance of hardmetals is to alloy the binder phase e.g. by adding small traces of $\mathrm{Cr}_{3} \mathrm{C}_{2}$, which during liquid phase sintering dissolve in the cobalt and enhance its corrosion resistance $[18,19]$. Other authors suggest that an addition of traces of rare earths improves the oxidation resistance of hardmetals [20,21]. Corrosion resistance of hardmetals can be further increased by controlling the dissolution of $\mathrm{W}$ in the binder phase by adjusting the carbon balance and hence the solubility product in the system $\mathrm{W}-\mathrm{C}-$ Co [22].

Since hardmetal degradation caused by both wear and corrosion starts at the tool surface, the lifetime of hardmetals can often be significantly extended by surface modifications. Typically CVD or PVD coatings are applied in order to increase surface corrosion resistance, but they are not applicable to many wear parts because of geometry, dimension and extreme working conditions. Besides, one of the problems in using protective coatings e.g. CVD alumina and CVD/PVD TiN or $\mathrm{TiC}$ in aggressive environments is the presence of open porosity and pinholes in the coating [23]. These local defects, attributed to the existence of cracks, to incomplete bonding between particles, and to interconnected porosity create direct paths through which the corrosive medium can gain access to the substrate material. Nitridation is an alternative method for controlling the chemical composition and microstructure at the surface of the hardmetal in order to improve its wear resistance [24-35]. By nitriding Ti-containing hardmetals a Ti $(\mathrm{C}, \mathrm{N})$ binder-free surface can be formed. The enhanced hardness of this phase leads to tremendous improvements in the wear resistance and in cutting performance [33-35].

Hardmetal cutting grades are also employed in wood-cutting applications. However, as referred to in Ref. [4], the environments associated with wood-cutting applications are characterized by a high moisture content (especially in green wood machining), which can affect the strength of the hardmetals and considerably shorten the tool lifetime due to the corrosive nature of the organic substances present in wood extracts [36-38].

The aim of this work is an investigation of the corrosion resistance of $\mathrm{WC}-\mathrm{TiC}-\mathrm{Co} / \mathrm{Ni}$-based hardmetals that were surface-treated in nitrogen. Because of the decrease in the amount of binder phase at the hardmetal surface due to the nitridation treatment and due to the higher corrosion resistance of Ti-containing compounds forming the hard surface layer
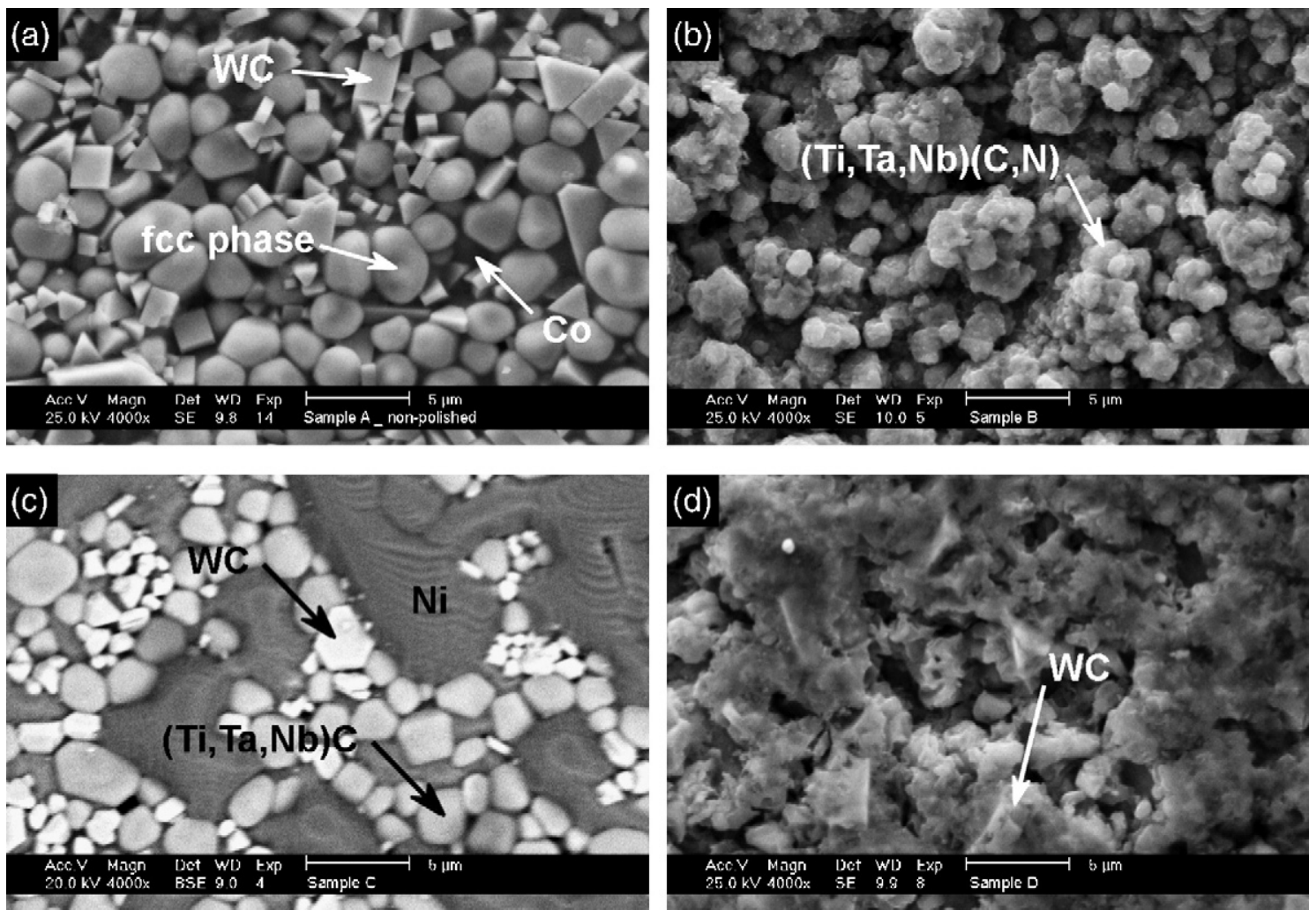

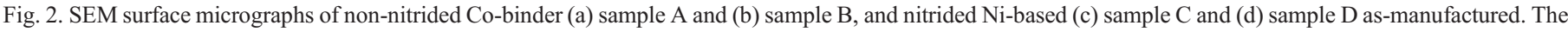

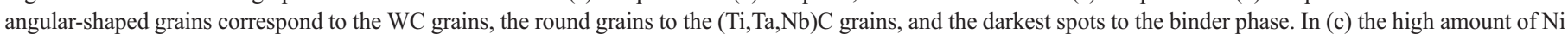
on the surface can be seen. 
Table 4

Surface chemical composition (weight percentage) of the investigated materials determined by EDX analysis ( ${ }^{1}$ non-polished, ${ }^{2}$ polished)

\begin{tabular}{llllrrl}
\hline Specimen & \multicolumn{6}{l}{ Chemical composition (wt.\%) } \\
\cline { 2 - 7 } & $\mathrm{Co}$ & $\mathrm{Ni}$ & $\mathrm{W}$ & \multicolumn{1}{c}{$\mathrm{Ti}$} & \multicolumn{1}{c}{$\mathrm{Ta}$} & $\mathrm{Nb}$ \\
\hline $\mathrm{A}^{1}$ & 11.7 & - & 60.6 & 8.9 & 7.5 & - \\
$\mathrm{A}^{2}$ & 7.9 & - & 57.4 & 15.0 & 13.0 & 2.5 \\
$\mathrm{~B}$ & 2.0 & - & 24.8 & 30.5 & 29.3 & 7.8 \\
$\mathrm{C}^{1}$ & 1.5 & 34.5 & 42.5 & 8.1 & 9.2 & - \\
$\mathrm{C}^{2}$ & - & 8.5 & 55.4 & 15.0 & 15.0 & 2.3 \\
$\mathrm{D}$ & 2.7 & 20.2 & 16.9 & 46.9 & 4.0 & 4.1 \\
\hline
\end{tabular}

compared to only W-containing ones, the nitrided (W,Ti)C-(Ta, $\mathrm{Nb}) \mathrm{C}-\mathrm{Co} / \mathrm{Ni}$ hardmetals are expected to show a considerable increase in the corrosion resistance.

\section{Experimental details}

\subsection{Samples}

Rectangular cemented carbide samples sized $16 \times 16 \times 4 \mathrm{~mm}^{3}$ $(l \times w \times t)$ were produced by industrial methods at Boehlerit $\mathrm{GmbH} \& \mathrm{Co} . \mathrm{KG}$. The pure Co respectively pure Ni-binder powders and the hard phase powders were mixed, pressed, and dewaxed at about $600{ }^{\circ} \mathrm{C}$. Afterwards, the samples were sintered in vacuum at $1450^{\circ} \mathrm{C}$. Half of both the samples with $\mathrm{Co}$ and the Ni-binder were then heat-treated under nitrogen atmosphere according to the procedure described in Ref. [24]. Non-nitrided samples with the $\mathrm{Co}$ and $\mathrm{Ni}$ binders are referred to as (A) respectively $(\mathrm{C})$, the nitrided samples with Co-binder are called (B), and those with Ni-binder are called (D) (Table 1).

\subsection{Electrochemical measurements}

Electrochemical measurements were carried out in $1 \mathrm{~N} \mathrm{H}_{2} \mathrm{SO}_{4}$ solution using a standard electrochemical polarization cell. A $3 \mathrm{M}$ $\mathrm{KCl} \mathrm{Ag} / \mathrm{AgCl}$ electrode, with a potential of $-207 \mathrm{mV}$ with respect to the standard hydrogen electrode $(\mathrm{SHE}=\mathrm{Ag} / \mathrm{AgCl}+207 \mathrm{mV})$, was used as reference electrode. The solution was open to air. All potentials are reported with respect to the $\mathrm{Ag} / \mathrm{AgCl}$ electrode. The reference electrode was placed outside the cell using a separated cell beaker, which is connected to the specimen surface by a liquid junction and a Haber-Luggin-Capillary. As counter electrode, a thin platinum rod $(\varnothing 6 \mathrm{~mm})$ was employed. The current density values are reported with respect to the area of the attacked surface, which was $100 \mathrm{~mm}^{2}$.

The measurements were performed at room temperature. Specimens were cleaned with ethyl alcohol in ultrasonic bath, rinsed with alcohol and dried with hot air before the experiment. Once the electrochemical cell was assembled and filled with the acid solution, the specimen was allowed to reach equilibrium at the corrosion potential at open circuit $\left(E_{\text {corr }}\right)$ for $1800 \mathrm{~s}$ before being polarized. A programmable WENKING POS2 potentiostat/galvanostat was employed for the measurements, which were performed in two distinct potential ranges, namely: (i) $-600 \mathrm{mV}$ to $+1400 \mathrm{mV}$ and (ii) $-600 \mathrm{mV}$ to $+400 \mathrm{mV}$. The influence of the scan rate on the electrochemical behavior of the sample groups was tested and then set to $600 \mathrm{mV} / \mathrm{h}$ in positive direction, unless otherwise specified.

\subsection{Microstructure characterization}

The microstructure of the specimens (at the surface and in cross-section) was investigated using optical microscopy (OM) and scanning electron microscopy (SEM) before and after the electrochemical measurements.

SEM analyses were performed on non-polished samples in order not to remove any possible corrosion products. To investigate the microstructure at the surface and the extension of the corrosion attack, sample cross-sections were embedded and polished on grinding discs with diamond particles with sizes of $9 \mu \mathrm{m}$ and $3 \mu \mathrm{m}$, and aqueous diamond suspension (MD-Chem OPS). Semiquantitative element analyses were performed in an SEM equipped with an energy dispersive X-ray (EDX) analyses unit. Morphological parameters such as average grain size, binder mean free path, and volume fraction were determined by image analyses.

In order to investigate the structural and composition alterations in the near-surface zone of the hardmetals caused by the corrosive attack in distinct potential ranges, X-ray diffraction measurements on attacked specimens were performed at the experimental station G3 at HASYLAB at DESY in Hamburg, Germany. The Low Incidence Beam Angle Diffraction (LIBAD) method [39] was applied in order to

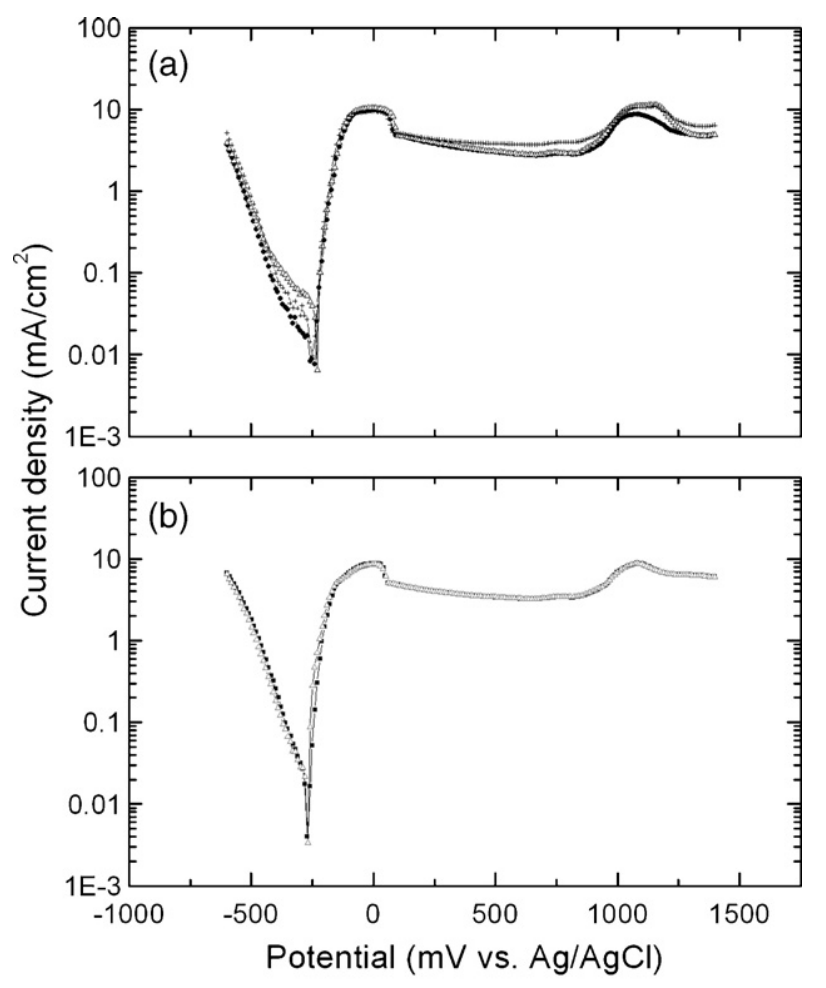

Fig. 3. Potentiodynamic polarization curves from separate measurements of different specimens of hardmetal (A) for (a) non-polished and (b) polished, showing the good reproducibility of experimental data. 

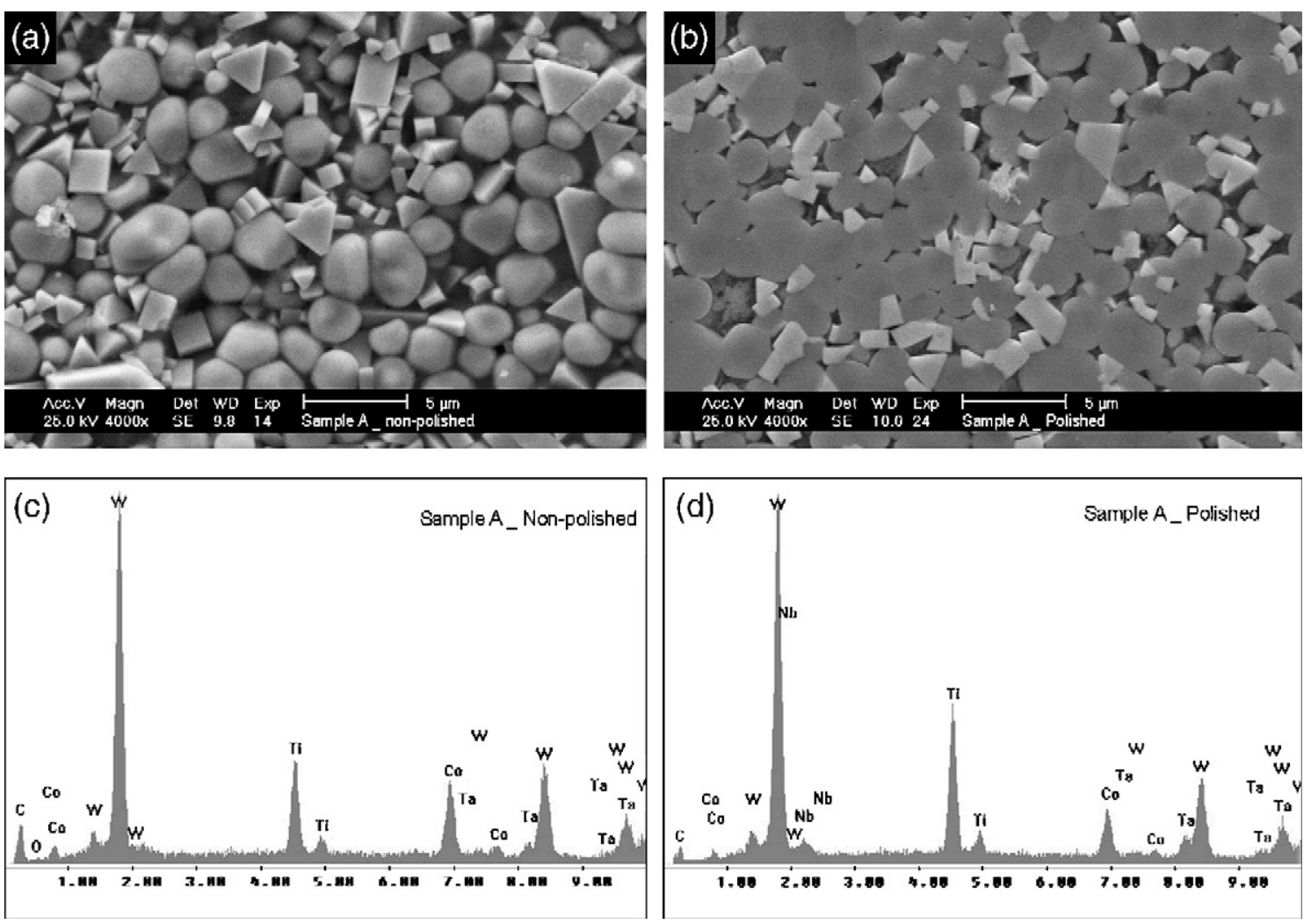

Fig. 4. SEM micrographs (SE mode) of the surface for (a) non-polished and (b) polished specimens of non-nitrided Co-binder sample A, and the corresponding EDX spectra (c) and (d) respectively.

reduce the penetration depth of the X-ray beam through the fcc enriched surface layer so as to keep information as much confined to the outer-surface layer as possible. The $\omega$ angle was set at $5^{\circ}$ and the area of incidence was $10 \mathrm{~mm} \times 1.5 \mathrm{~mm}$.

\section{Results}

\subsection{Sample microstructure before corrosion tests}

All samples show a uniform phase distribution in the bulk (Fig. 1), where angular shaped WC grains and round $(\mathrm{Ti}, \mathrm{Ta}, \mathrm{Nb}) \mathrm{C}$ grains are embedded in the Co or the Ni-binder phase. Samples A and C (Table 1), which were not subject to nitridation, show a homogeneous phase distribution throughout

Table 5

Eletrochemical parameters of investigated materials in $1 \mathrm{~N} \mathrm{H}_{2} \mathrm{SO}_{4}$ solution ( ${ }^{1}$ non-polished, ${ }^{2}$ polished)

\begin{tabular}{|c|c|c|c|c|c|c|}
\hline \multirow[t]{2}{*}{ Specimen } & $E_{\text {corr }}$ & $i_{\text {corr }}$ & $i_{\text {crit }}$ & $i_{\mathrm{pp}}$ & $b_{\mathrm{c}}$ & $b_{\mathrm{a}}$ \\
\hline & $(\mathrm{mV})$ & $\left(\mathrm{mA} / \mathrm{cm}^{2}\right)$ & $\left(\mathrm{mA} / \mathrm{cm}^{2}\right)$ & $\left(\mathrm{mA} / \mathrm{cm}^{2}\right)$ & $(\mathrm{mV} / \mathrm{dec})$ & $(\mathrm{mV} / \mathrm{dec})$ \\
\hline $\mathrm{A}^{1}$ & -250 & 0.005 & 9.39 & 3.717 & 111 & 42 \\
\hline$A^{2}$ & -270 & 0.015 & 8.83 & 3.274 & 114 & 40 \\
\hline B & -360 & 0.013 & $\sim 0.2$ & $\sim 0.2$ & 127 & - \\
\hline $\mathrm{C}$ & -170 & 0.013 & 4.46 & 0.601 & 158 & 83 \\
\hline D & -150 & 0.008 & 1.08 & 0.132 & 170 & 89 \\
\hline
\end{tabular}

$E_{\text {corr }}$, corrosion potential; $i_{\text {corr }}$, corrosion current density; $i_{\text {crit }}$, critical current density; $i_{\mathrm{pp}}$, pseudopassivation current density; $b_{\mathrm{c}}$ and $b_{\mathrm{a}}$, cathodic and anodic Tafel slopes. Sample B does not present a true pseudopassivation behavior.

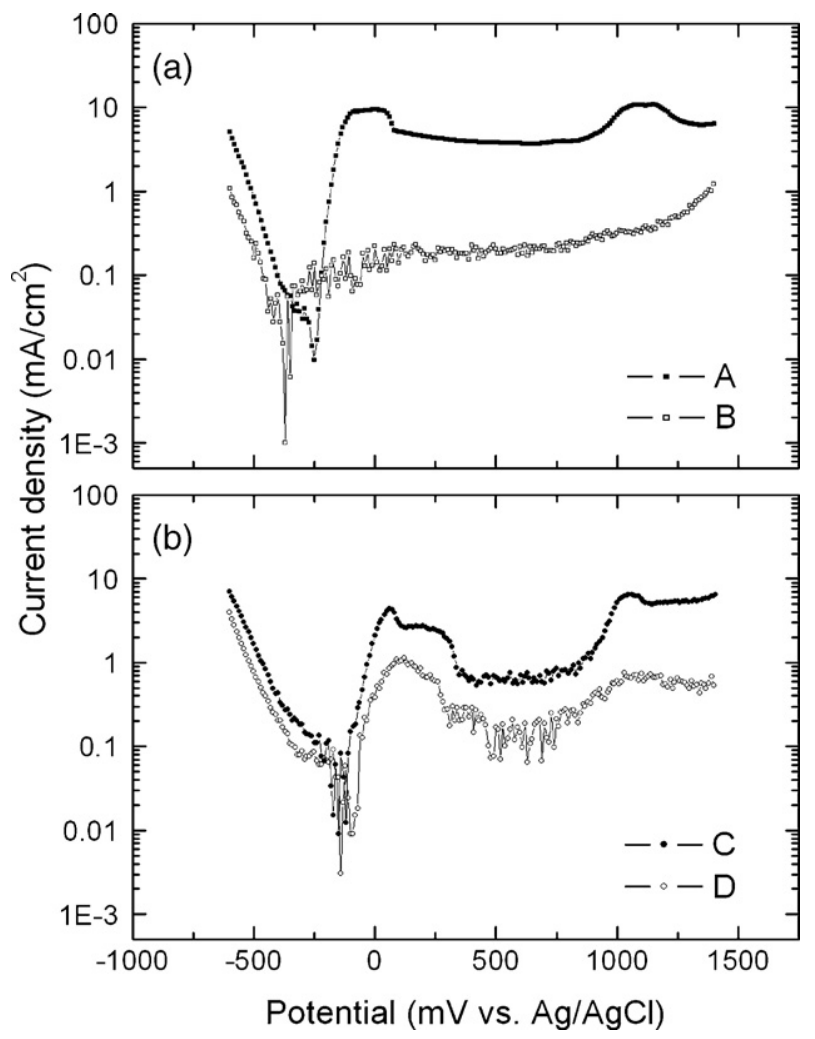

Fig. 5. Potentiodynamic polarization curves for specimens A, B, C, and D showing the effect of nitridation on the electrochemical behavior of hardmetals with (a) Co and (b) $\mathrm{Ni}$ as the binder metal. 

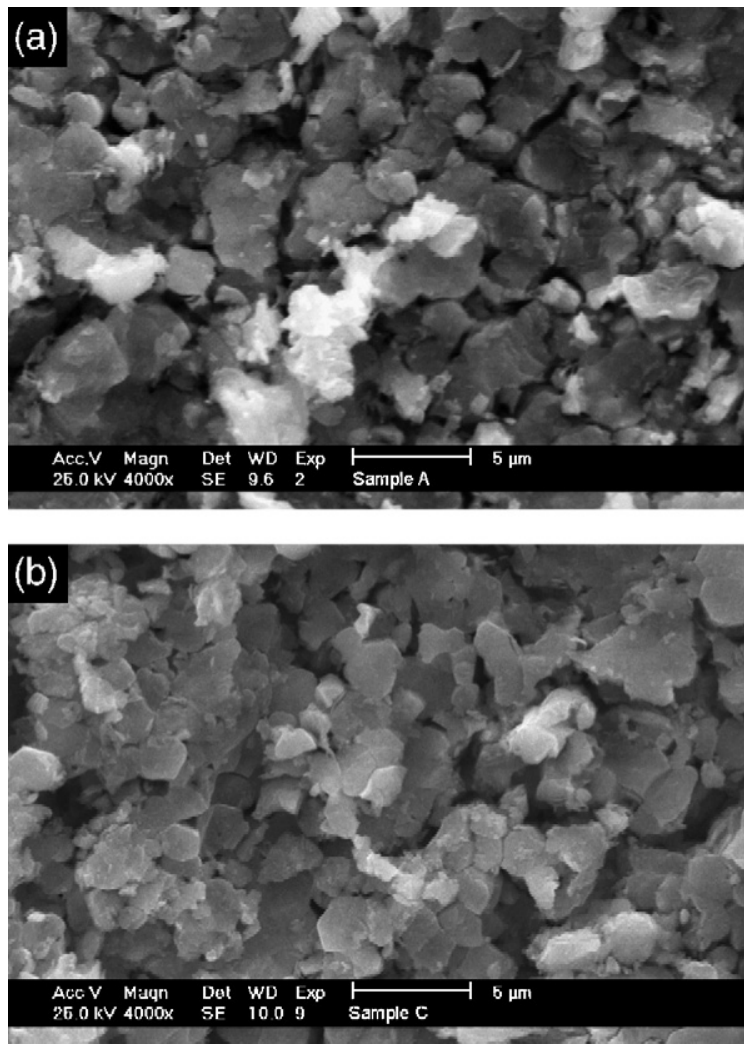

Fig. 6. SEM micrographs (SE mode) of the outer-surface of the attacked nonnitrided (a) Co-based sample A and (b) Ni-based sample C.

their whole volume. The average grain sizes of the WC and fcc phases are $1.5 \mu \mathrm{m}$ and $3 \mu \mathrm{m}$ respectively (Table 2 ). The Co and Ni-binder segments vary in size, but do not exceed $2 \mu \mathrm{m}$ in maximum length (Table 2). In all sample groups different specimens had identical phase volume fractions (Table 2).

Nitridation of the samples with both Co-binder (sample B) and Ni-binder (sample D) produced an fcc-rich near-surface zone layer (Fig. 1). The surface roughness depends on the binder phase and it is different for nitrided and non-nitrided samples, however there is no clear correlation between surface roughness and nitridation treatment (Table 3). SEM images of the surface of the samples B and D show the effect of nitridation on their microstructure (Fig. 2). Compared to the non-nitrided samples the near-surface zone of the nitrided samples is enriched in $\mathrm{Ti}$ and to some extend also in $\mathrm{Ta}$ and $\mathrm{Nb}$ (Table 4). EDX-analyses in the SEM and TEM as well as X-ray diffraction indicate that the main component of the near-surface zone is an $(\mathrm{Ti}, \mathrm{Ta}, \mathrm{Nb}, \mathrm{W})(\mathrm{C}, \mathrm{N})$ fcc-phase. Besides this fcc-phase, the nearsurface zone of the nitrided layers also contains some small WC grains. The grain size of the $(\mathrm{Ti}, \mathrm{Ta}, \mathrm{Nb}, \mathrm{W})(\mathrm{C}, \mathrm{N})$ phase is smaller in the near-surface zone of the nitrided samples with Ni-binder (B) than those with Co-binder (D). Whereas the distribution of the $(\mathrm{Ti}, \mathrm{Ta}, \mathrm{Nb}, \mathrm{W})(\mathrm{C}, \mathrm{N})$ phase is homogeneous in the surface layer of the samples with Co-binder (B), in the near-surface layer of the nitrided samples with Ni-binder (D) clusters of (Ti, $\mathrm{Ta}, \mathrm{Nb}, \mathrm{W})(\mathrm{C}, \mathrm{N})$ form a compact net surrounding the $\mathrm{WC}$ grains. In the case of non-nitrided samples with Ni-binder (C), traces of Ni were found on the sample surface (Fig. 2c).
Cross-section micrographs of the nitrided samples reveal that the average thickness of the fcc layer is about $10 \mu \mathrm{m}$ for the nitrided samples with Co-binder (B) and slightly smaller, about $5 \mu \mathrm{m}$, for the nitrided samples with Ni-binder (D). This layer thickness has been shown by other authors e.g. $[28,35]$ to be sufficient for significantly increasing the tool lifetime of hardmetals and cermets in cutting and milling operations. Besides, several CVD and PVD coatings are deposited onto hardmetals as films with total thickness around 4-20 $\mu \mathrm{m} \mathrm{e.g.}$ [40-42], which provide excellent wear resistance in spite of their rather limited thickness.

\subsection{Typical hardmetal potential-current density curves}

The potentiodynamic scans are well reproducible, particularly in case of the polished specimens (Fig. 3). The polarization behavior of our samples agrees well with earlier potentiodynamic measurements on WC-Co-based hardmetals shown in Refs. $[6,7,10,13,14]$. The potentiodynamic curve can be described by an exponential increase in the cathodic current density as a function of the polarization. The increase in cathodic and anodic current densities indicates activation control and can be described by the early empirical equation by Tafel [43]:

$$
\Delta E=E-E_{\text {corr }}=a \pm b \log |i|
$$

$a$ and $b$ are characteristic constants of the electrode system, $b$ is the so-called Tafel slope, which provides information on the reaction rate. The \pm sign is for anodic $\left(b_{\mathrm{a}}\right)$ and cathodic $\left(b_{\mathrm{c}}\right)$ overpotentials. Eq. (1) only holds for relatively high overpotentials (i.e., approximately $0.1 \mathrm{~V}$ or higher).

In the anodic branch of the curve we initially observe an exponential increase in the current density with increasing potential $E>E_{\text {corr }}$, at $E \sim-200 \mathrm{mV}$ the corrosion rate decreases and the critical current density value $\left(i_{\text {crit }}, E_{\text {crit }}\right)$ is reached. For $E>E_{\text {crit }}$ the current density decreases abruptly, and remains nearly independent on the applied potential in the pseudopassive region. Human and Exner [7] call this region pseudopassive because the current density at the critical point drops but still remains several orders of magnitude higher than those observed in a typical passivation phenomenon. Since here the current density is not exactly constant we chose the minimum current density $i_{\mathrm{pp}}$ as a characteristic value to describe the pseudopassive part of the potential-current density curve. For $E \sim+750 \mathrm{mV}$ oxidation of WC starts $[7,13]$ and a local maximum of current density arises for $\mathrm{E} \sim+1100 \mathrm{mV}$ in the transpassive region.

In order to assess the influence of surface roughness on the electrochemical behavior of the samples potentiodynamic tests were performed for non-polished and polished specimens (Fig. 4) of the non-nitrided samples with Co-binder (A). The experiments did not reveal significant differences in the corrosion behavior of the as-manufactured and the polished samples (Table 5). Thus, small inhomogeneities of the near-surface zone produced by the manufacturing process appear to be of minor influence on the corrosion behavior of the hardmetals so 

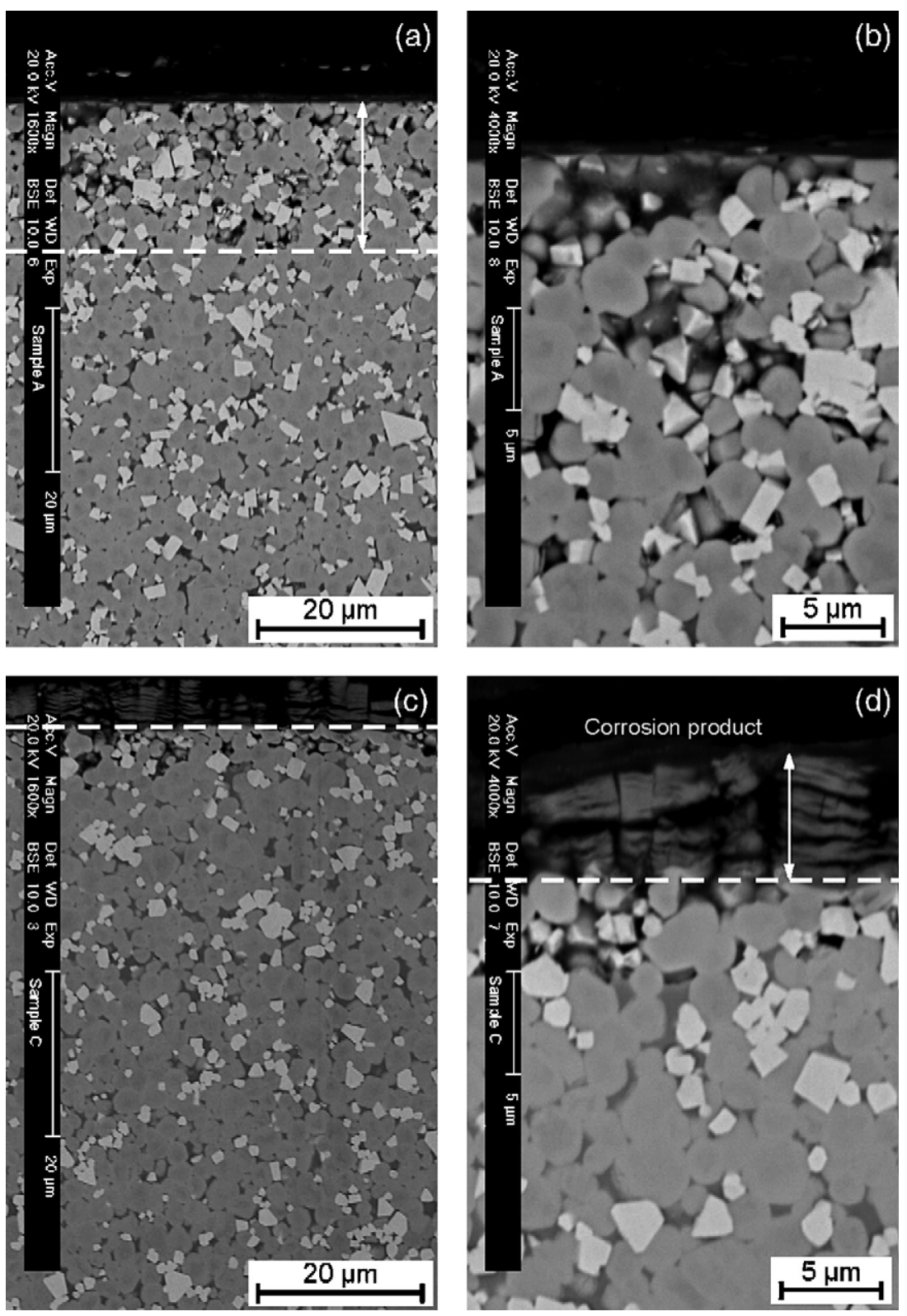

Fig. 7. SEM micrographs of the cross-section of corroded sample $A(a, b)$ and sample $C(c, d)$ after polarization at $+1400 \mathrm{mV}$. The white line in (a) indicates the interface between Co-depleted zone (where the grains belonging to the hard phase seem loosely attached) and the non-attacked bulk, whereas in (c) it indicates the interface between the binder-depleted bulk and the corrosion product (formed by the hard phase skeleton and tungsten oxide). In (d) the corrosion product is shown in detail.

that we refer to the measurements made on non-polished samples (Table 5).

\subsection{Influence of nitridation on the potential-current density curves}

A comparison of the potentiodynamic polarization curves of specimens both with Co and Ni-binder shows that the current densities of the nitrided sample groups are always lower than those of the non-nitrided samples (Fig. 5).

The potential-current density curves of the nitrided hardmetals with Ni-binder have the same typical features as those of the non-nitrided hardmetals. The Tafel slopes $b_{\mathrm{c}}^{\mathrm{D}}$ and $b_{\mathrm{a}}^{\mathrm{D}}$ (Table 5) obtained for nitrided samples with Ni-binder (D) differ only slightly from those of the non-nitrided samples (C). This indicates that the nitridation process did not affect the corrosion rate of the binder. The curve shape at the critical current density is slightly different for the nitrided samples (D) and the nonnitrided samples $(\mathrm{C})$, which might be attributed to traces of $\mathrm{Ni}$ at the surface of the non-nitrided samples (C).

In contrast to the hardmetals with Ni-binder, the anodic region of the potentiodynamic polarization curve of the nitrided samples with Co-binder (B) is significantly different from that of the non-nitrided samples (A). The nitrided samples (B) exhibit a distinct "pseudopassive" behavior: the current density in the anodic region is nearly independent of the applied potential. The nitrided samples with a Co-binder do not show a true critical value (maximum) of the current density. Despite the 

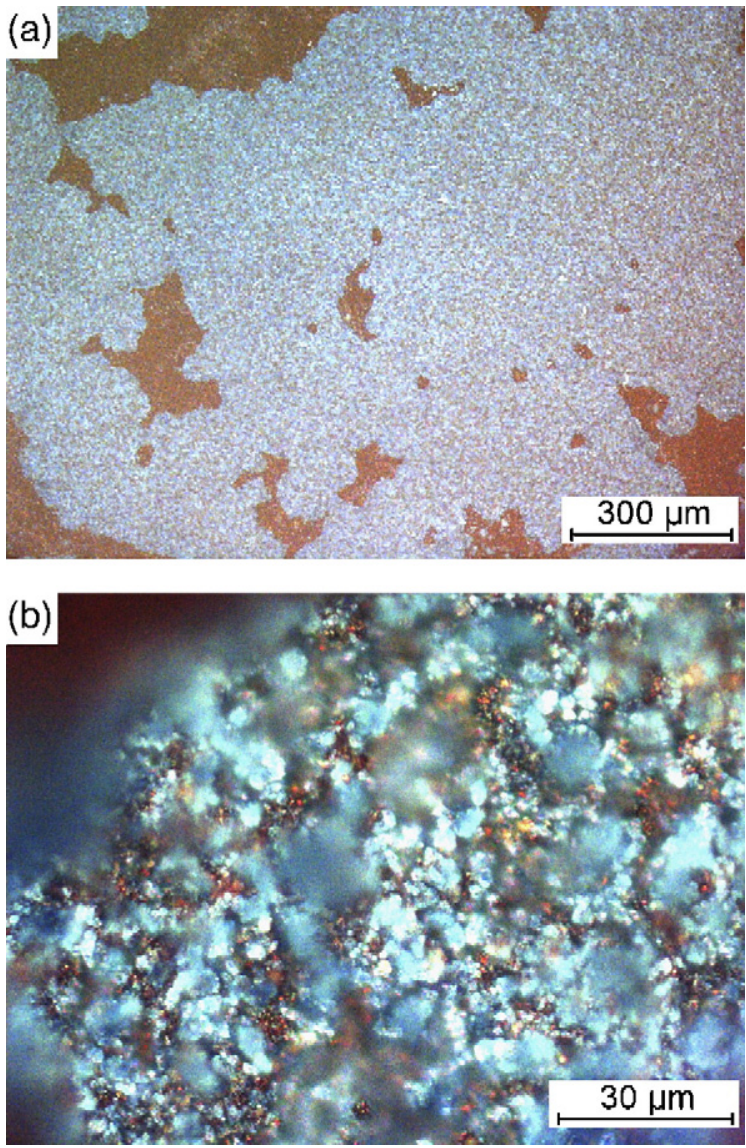

Fig. 8. Optical micrographs of the surface of the corroded sample B after polarization test from -600 to $+1400 \mathrm{mV}$ in $1 \mathrm{~N} \mathrm{H}_{2} \mathrm{SO}_{4}$. In (a) the blue areas correspond to the deposition of the corrosion product. In (b) the blue deposit is shown at higher magnification $(100 \times)$.

lower current density values of the nitrided samples with a Cobinder, nitridation shifts the corrosion potential to a less noble value $\left(E_{\mathrm{corr}}^{\mathrm{B}}-\approx-360 \mathrm{mV}\right.$ compared to $\left.E_{\mathrm{corr}}^{\mathrm{A}} \approx-250 \mathrm{mV}\right)$.

\subsection{Microstructure of the corroded samples}

Corrosive attack in hardmetals polarized at anodic potentials as high as $+1400 \mathrm{mV}$ (within the $\mathrm{WC}$ oxidation range) leads to the formation of a light-blue deposit with a flake-like morphology (Figs. 6-8) on the non-nitrided samples (A,C), which is characteristic of hardmetals submitted to anodic polarization within the oxidation range of WC [44] (this lightblue layer can easily be lost during sample preparation). EDX

Table 6

Surface chemical composition (weight percentage) of the corroded specimens (non-polished) determined by EDX analysis

\begin{tabular}{llllrll}
\hline \multirow{2}{*}{ specimen } & \multicolumn{7}{l}{ Chemical composition (wt.\%) } \\
\cline { 2 - 7 } & $\mathrm{Co}$ & $\mathrm{Ni}$ & $\mathrm{W}$ & $\mathrm{Ti}$ & $\mathrm{Ta}$ & $\mathrm{Nb}$ \\
\hline $\mathrm{A}$ & - & - & 56.9 & 15.1 & 12.8 & 2.6 \\
$\mathrm{~B}$ & - & - & 71.3 & 5.9 & 13.3 & - \\
$\mathrm{C}$ & - & 1.4 & 56.8 & 13.5 & 14.2 & 2.1 \\
$\mathrm{D}$ & - & 1.1 & 16.9 & 57.9 & 14.8 & 5.9 \\
\hline
\end{tabular}

analyses indicated that oxygen is present at the surface of the corroded non-nitrided hardmetals. The light-blue deposit (Fig. 8) is enriched in $\mathrm{W}$ (Table 6) and presumably is $\mathrm{WO}_{3}$ formed by oxidation of the $\mathrm{W}$ at high corrosion potentials $[10,45]$. The porosity of the light-blue oxide layer might be associated with binder phase depletion. A corrosion product with similar characteristics was observed in investigations of corrosion properties of $\mathrm{WC}-\mathrm{Co}$-based hardmetals carried out by e.g. $[6,10,44,46]$.

An oxide layer similar in color (Figs. 9 and 10) and composition (Table 6), but different in morphology to those on the non-nitrided samples is found on the nitrided samples with Co-binder (B). In case of the nitrided samples with Ni-binder (D) only a slight change of color could be visually perceived after polarization. However, a sponge-like net including small
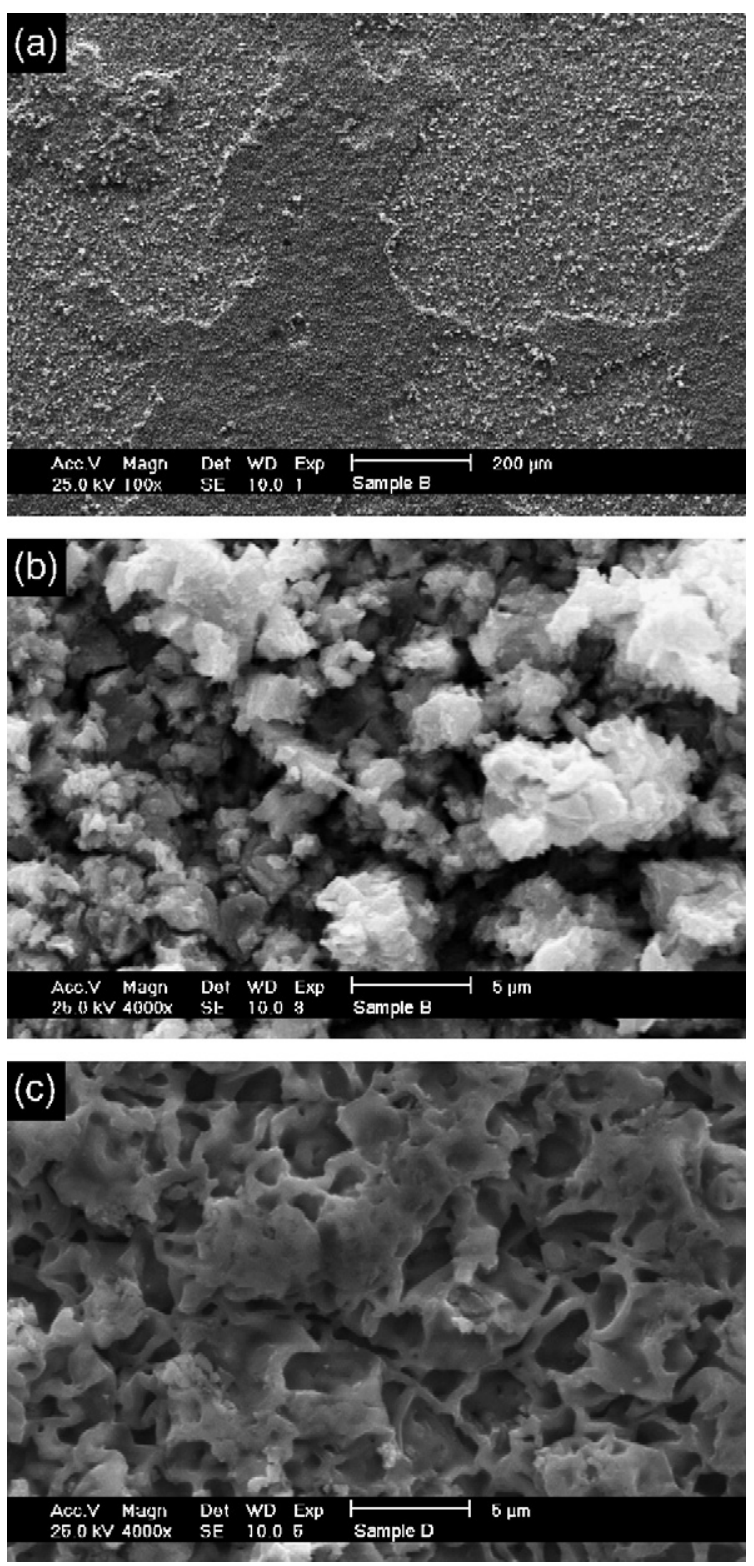

Fig. 9. SEM micrographs (SE mode) of the near-surface zone of (a) attacked surface of sample B, shown in (b) in detail, and (c) sample D. 

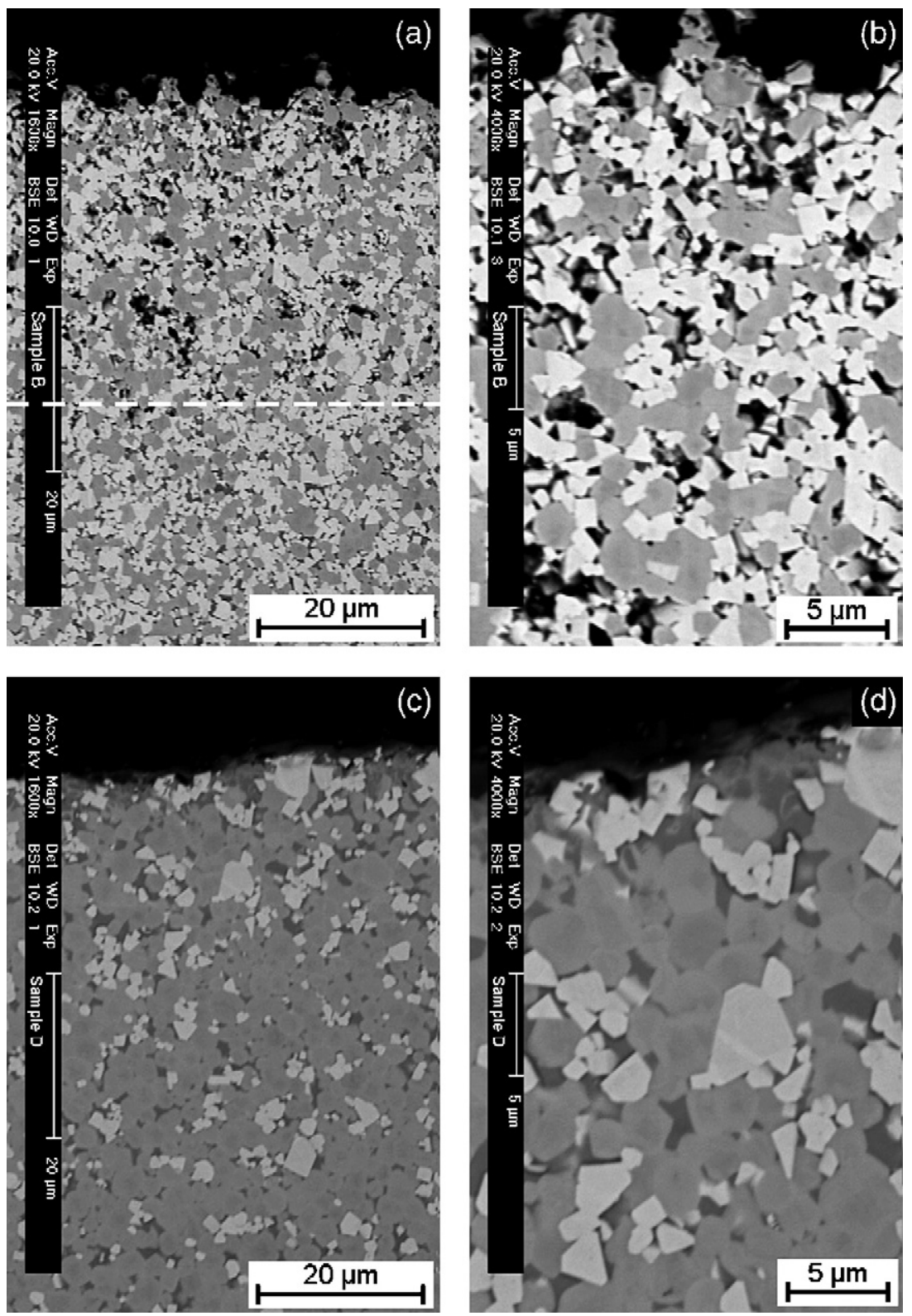

Fig. 10. SEM micrographs of the cross-section of corroded sample B (a, b) and sample D (c, d) after polarization at $+1400 \mathrm{mV}$. The white line in (a) indicates the interface between Co-depleted zone (where the grains belonging to the hard phase seem loosely attached) and the non-attacked bulk.

light-colored chips is formed on the surface (Fig. 11). EDX linescans indicate (Table 6) that the sponge-like structure is the remaining $(\mathrm{Ti}, \mathrm{Ta}, \mathrm{Nb}, \mathrm{W})(\mathrm{C}, \mathrm{N})$, while the light-colored particles presumably are $\mathrm{WO}_{3}$. Almost no Co respectively Ni was present on the surface of both non-nitrided and nitrided corroded hardmetals.

The attacked area of the specimens subjected to polarization at lower anodic potential $(+400 \mathrm{mV})$ is already considerably depleted of the binder metal, as revealed by the EDX analyses. SEM micrographs of all attacked specimens are shown in Fig. 12. The dissolution of the binder produces a porous structure delimited by the hard phase skeleton.

A typical XRD diffractogram taken in grazing incidence at the surface of a corroded specimen (the electrochemical measurement was interrupted in the pseudopassive region) is shown in Fig. 13.
All specimens display very marked WC reflections and extremely weak reflections of the metallic binder $\mathrm{Co} / \mathrm{Ni}$. The diffractograms of the nitrided specimens show additional reflections of the (Ti, Ta, $\mathrm{Nb})(\mathrm{C}, \mathrm{N})$ phase. No reflections associated with $\mathrm{CoSO}_{4} / \mathrm{NiSO}_{4}$ (expected at lower angles) or oxides (e.g. $\mathrm{CoO} / \mathrm{NiO}$ ) could be obtained despite measuring in grazing incidence and with a high photon flux.

\section{Discussion}

The influence of the nitridation process on the corrosion resistance of (W,Ti)C-based hardmetals both with $\mathrm{Co}$ and $\mathrm{Ni}$ as the binder phase was investigated. The modified hardmetals show significantly improved corrosion resistance. This effect is discussed in detail in the following paragraphs. 

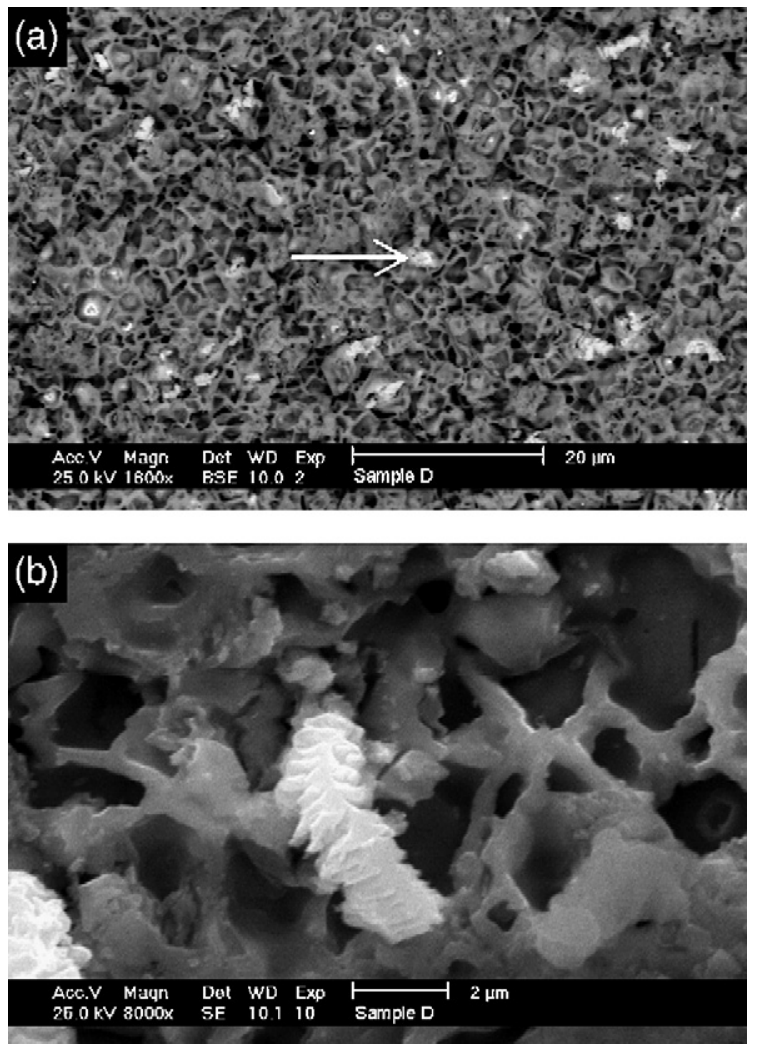

Fig. 11. SEM micrographs of the near-surface zone of corroded sample D. The arrow in (a) indicates one of the dispersed compounds, which is shown in detail in (b).

\subsection{Corrosion mechanism in hardmetals}

Corrosion of hardmetals in aggressive media progresses mainly by binder dissolution $[3,6,7,47,48]$. The experiments performed showed that this is also the case for $\mathrm{WC}-\mathrm{Co} / \mathrm{Ni}$ hardmetals to which a large amount of $(\mathrm{Ti}, \mathrm{Ta}, \mathrm{Nb}) \mathrm{C}$ was added and also for these hardmetals with a nitrided surface layer.

Zur Megede and Heitz [49] were the first authors to stress the existence of galvanic coupling effects between the cathodic WC phase and the anodic metallic matrix in a seminal work reporting on the comparison between the corrosion behavior of hardmetals with $\mathrm{Co}$ and Ni-based binders.

\subsubsection{The first stage of corrosion}

At potentials between the corrosion potential $E_{\text {corr }}$ and about $-30 \mathrm{mV}$ and $+60 \mathrm{mV}$ respectively for Co and Ni-based hardmetals, the binder dissolution can be described by the anodic reactions:

$\mathrm{Co} \rightarrow \mathrm{Co}^{2+}+2 \mathrm{e}^{-}$respectively $\mathrm{Ni} \rightarrow \mathrm{Ni}^{2+}+2 \mathrm{e}^{-}$

The corrosion rate is enhanced by the galvanic coupling. The Co ions dissolved in the electrolyte can produce precipitates according to Ref. [50]:

$$
\begin{aligned}
& \mathrm{Co}^{2+}+\mathrm{SO}_{4}^{-2} \rightarrow \mathrm{CoSO}_{4} \\
& \mathrm{Co}^{2+}+2 \mathrm{OH}^{-} \rightarrow \mathrm{Co}(\mathrm{OH})_{2}
\end{aligned}
$$

Similar reactions hold for $\mathrm{Ni}$. The current densities relate to the amount of binder consumed in the process and to the diffusion of metal ions to the electrolyte, which depends on the access of the corrosive medium to the binder. This access is determined to a great extent by the morphology (i.e. binder mean free path) in the sample (Fig. 14). After binder dissolution a hard phase skeleton is left at the surface.

\subsubsection{Pseudopassivity}

At higher potentials usually a pseudopassive region exists in the potentiodynamic curve of $\mathrm{WC}-\mathrm{Co} / \mathrm{Ni}$ hardmetals $[7,14]$. Human and Exner [13] attributed pseudopassivity to the formation of an anodic film e.g. of $\mathrm{CoWO}_{4}$ on the hardmetal surface. This kind of anodic film was not revealed here by our synchrotron X-ray diffraction measurements in grazing incidence with a high photon flux. Besides, there was no indication of the existence of such a film in microscopic analyses, as already pointed out by other authors [14].

Another argument against the presence of oxide/salt films in the samples subjected to pseudopassive anodic potentials is that they would be expected to form at the interface between the intact hardmetal structure and the hard phase skeleton. Under continuous corrosive attack these films are supposed to redissolve in the electrolyte or still, the further dissolution of the binder could lead to a disintegration of the hard phase skeleton to which the film would adhere. In true passivity, all these effects would lead to a rather oscillating current density response [51], since the structure of the reactivity barrier would be changing. Such an oscillatory behavior was not observed in our measurements. This leads to arguments solely based on the role that the microstructure of the attacked hardmetals play in the ion exchange rate, as already indicated by other authors e.g. Ref. [14].

In contrast to Human and Exner [13], Sutthiruangwong and Mori [14] claim that the increasing length of the Co diffusion path accounts for the pseudopassive behavior in $\mathrm{Co} / \mathrm{Ni}$-based hardmetals, because after the dissolution of the binder metal by anodic polarization, $\mathrm{Co} / \mathrm{Ni}$ ions $\mathrm{Co}^{2+} / \mathrm{Ni}^{+2}$ have to diffuse through the remaining porous WC skeleton. Since diffusion through this medium is slower than free diffusion and even much slower than convection, the mass transport current flow is decreased. Also porosity, pore size, and tortuosity of the porous layer have an effect on diffusion by making it difficult for the binder ions to diffuse towards the surface. Sutthiruangwong and Mori [14] also argue that no layer such as $\mathrm{CoWO}_{4}$ or $\mathrm{CoSO}_{4}$ had been found at the interface between the WC skeleton and the hardmetal. Our experimental results (SEM, X-ray diffraction) also do not reveal these layers, and we thus follow Sutthiruangwong and Mori's [14] arguments. In addition to Ref. [14] we think that it is important to consider the morphology of the hard phase skeleton and its porosity. In those cases where pores are closed or the hard phase skeleton is very dense, binder metal ion exchange is limited to ion diffusion through the skeleton towards the surface in contrast to binder metal ions reaching an inner hard phase-electrolyte interface (Fig. 14b). A dense hard phase skeleton restricts the solvent's access to fresh binder metal 

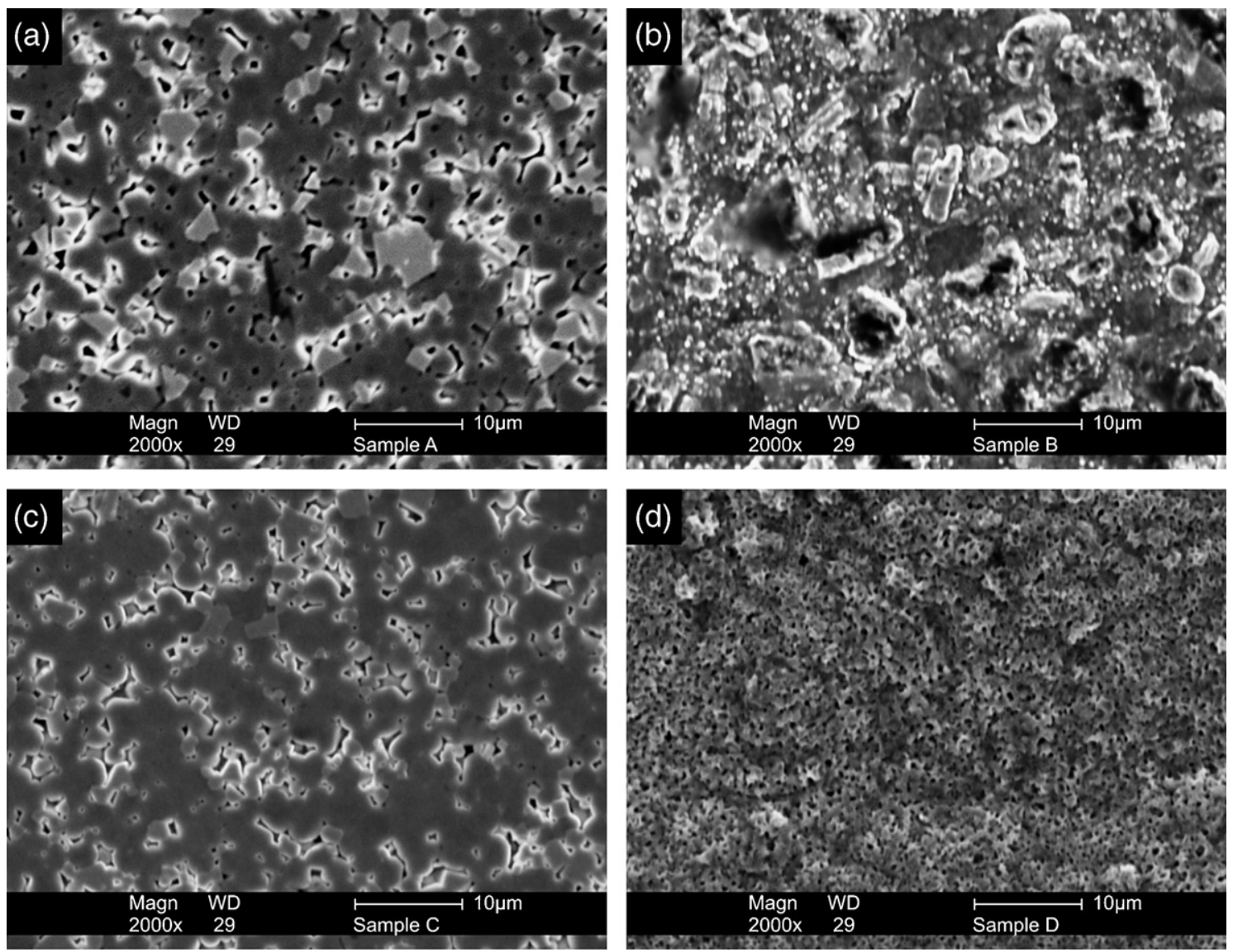

Fig. 12. SEM micrographs of the surface of corroded Co-binder (a) non-nitrided and (b) nitrided and Ni-binder (c) non-nitrided and (d) nitrided after polarization at $+400 \mathrm{mV}$.

towards the bulk. The limiting case of such a dense hard phase skeleton is the case of closed pores, where the solvent is denied access to the binder in the bulk of the hardmetals almost completely (Fig. 14a) and ions exchange is only via binder ions diffusing towards the former hardmetal surface. We observe that in the hardmetals investigated in this study, the binder mean free path decreases from the surface into the

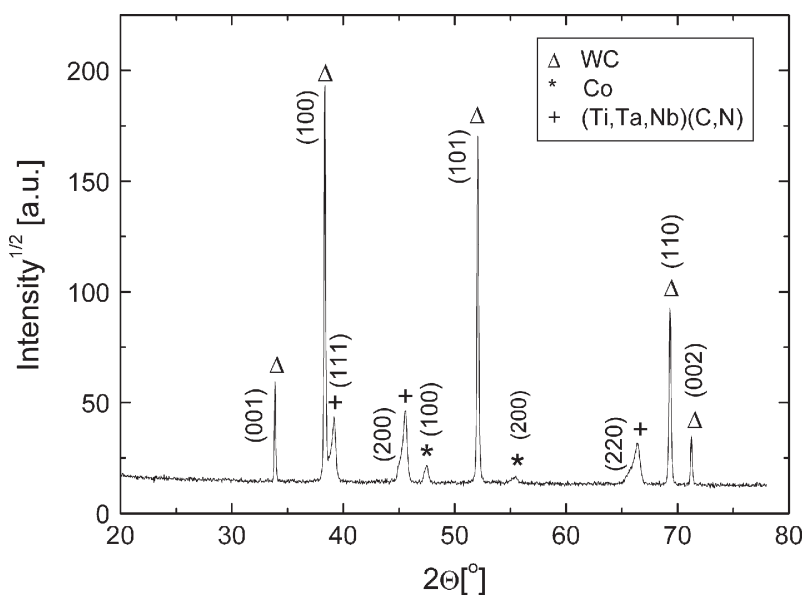

Fig. 13. X-ray diffractrogram of the corroded nitrided Co-binder hardmetal (B) after polarization at $+400 \mathrm{mV}$. bulk (Fig. 15), thus progressive corrosion makes it increasingly more difficult for the corrosive medium to reach the binder (Fig. 15). (a)

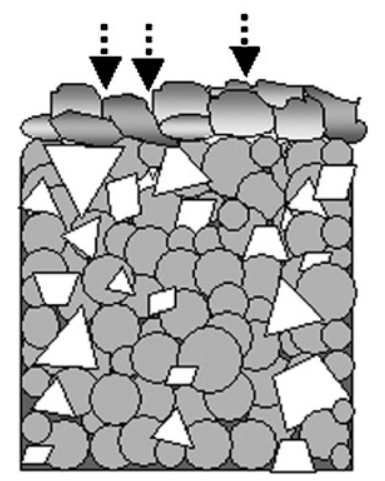

$(\mathrm{Ti}, \mathrm{Ta}, \mathrm{Nb}) \mathrm{C}$

$\rightleftarrows$ Corrosion Product (b)

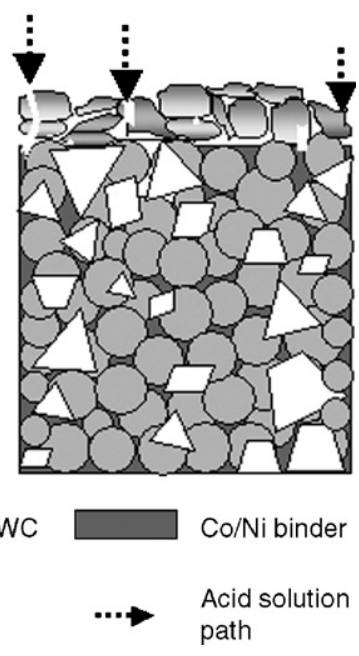

Fig. 14. Schematic of the microstructure in corroded samples. The case in which the skeleton is very dense (closed porosity) is represented in (a), whereas in (b) the lower density (open porosity) of the structure allows the deeper access of the corrosive medium and diffusion of ions from inner regions of the bulk. 

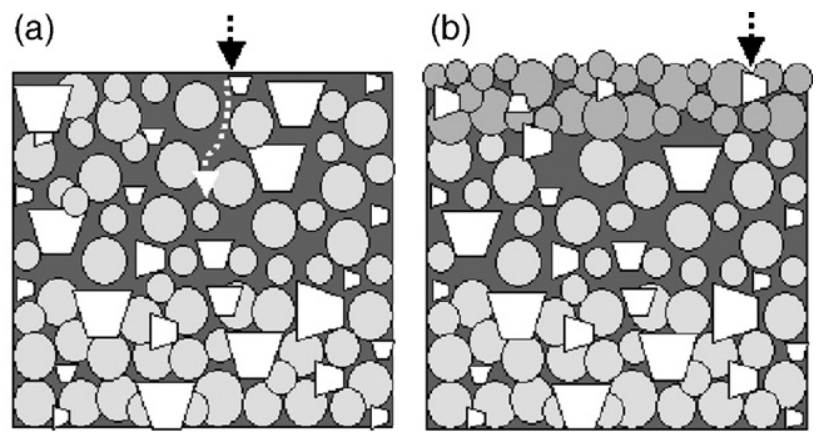

(c)

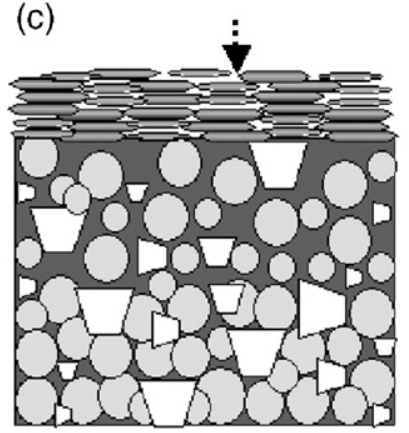

(d)
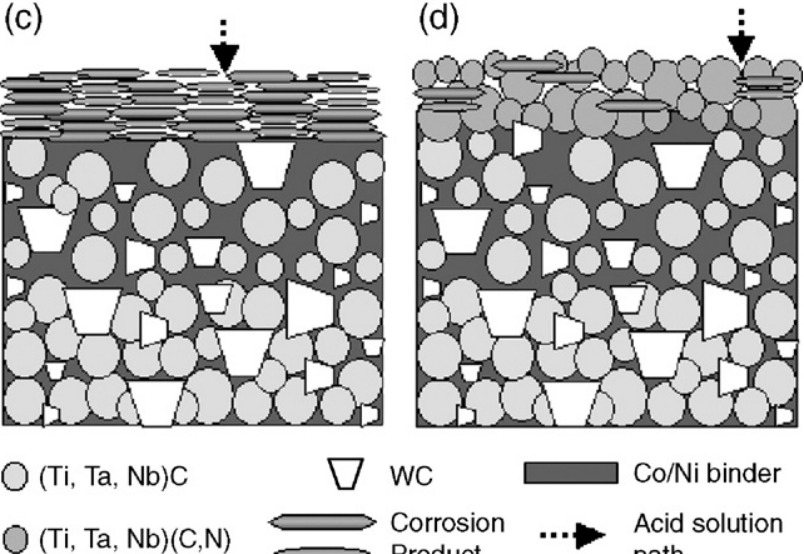

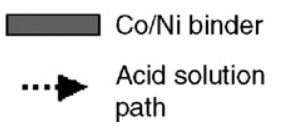

Fig. 15. Schematic of the structure of non-nitrided and nitrided hardmetal before and after binder dissolution at the surface region, showing the effect of the morphology on the binder free mean path and the solvent access to the binder. In (a) the decreasing binder mean free path towards the bulk would be the main mechanism in the non-nitrided sample groups to hinder further binder dissolution and cause the current drop. In (b) the harder and more corrosion resistant $(\mathrm{Ti}, \mathrm{Ta}, \mathrm{Nb}, \mathrm{W})(\mathrm{C}, \mathrm{N})$ layer would hinder the solvent access. Binder dissolution would then take place at the immediate binder amount exposed to the medium. (c) Once the binder dissolution occurred at the surface region of the non-nitrided sample group, the relatively dense hard phase skeleton would be an additional obstacle to the entrance of solvent. (d) In the corroded nitrided sample no binder is left on the layer and the corrosion product would restrain further access to the binder in the bulk.

Ni-binder hardmetals have been shown to be more resistant to corrosion and less sensitive to the nature of the corrosive media than Co-binder ones $[3,7,11,52]$, although according to Wentzel and Allen [3] that it is not always the case if slurry erosion is involved in the corrosion process. Our results fit well in the general picture, since all Ni-binder hardmetals showed a higher corrosion resistance both regarding the electrochemical parameters and the extension of the binder-depleted zones.

In the non-nitrided samples with Ni-binder (C), traces of $\mathrm{Ni}$ appeared due to segregation of the binder phase at temperatures above $1290{ }^{\circ} \mathrm{C}$ (Fig. 2c). The corrosion mechanism in case of the sample with these traces of Ni differs only slightly from those already discussed, since binder dissolution takes place in two steps: first, the Ni patches on the surface are dissolved. Once this Ni amount has leached out, the acid solution attacks the binder in the bulk. At this moment current densities decrease because the areas occupied by the binder in the inner parts of the hardmetal are more difficult to access by the corrosive medium due to tortuosity.

\subsubsection{Corrosion at higher potentials}

At high potentials (about $800 \mathrm{mV}$ ) WC oxidation occurs. The anodic reaction in $1 \mathrm{~N} \mathrm{H} 2 \mathrm{SO} 4$ takes place according to the following equation [53]:

$\mathrm{WC}+5 \mathrm{H}_{2} \mathrm{O} \rightarrow \mathrm{WO}_{3}+\mathrm{CO}_{2}+10 \mathrm{H}^{+}+10 \mathrm{e}^{-}$

The lower current densities may be attributed to the formations of tungsten oxide at the sample surface or in the bulk, as a deposit around the WC grains (see the blue deposit in Fig. 8), depending on the morphology of the skeleton. The oxide layer restricts the access of the acid solution to the inner binder (Fig. 16). The corrosion resistance of the oxide is strongly superior to the binder [14] and since ohmic resistance increases proportionally to the oxide layer thickness $[7,10]$, this may also explain the lower current densities associated with the samples with Ni-binder, which present a thicker oxide layer on the surface compared to samples with Co-binder. Thus, corrosion resistance of the Co-based hardmetals is also inferior to Ni-based hardmetals at higher potentials.

\subsection{Influence of the nitridation on the corrosion behavior}

The electrochemical behavior of nitrided hardmetals with fcc-rich near-surface zone so far has not been investigated. The results presented in this work show that the nitridation treatment can strongly enhance the corrosion resistance of (W,Ti)C-based hardmetals.

The main reason for the increase in corrosion resistance by nitridation is the formation of a binder-poor to binder-free nearsurface zone. The $(\mathrm{Ti}, \mathrm{Ta}, \mathrm{Nb})(\mathrm{C}, \mathrm{N})$ surface layer extends up to several micrometers and it is almost dense. On the one hand, the closed porosity of the layer and the reduction of the binder mean free path compared to the non-nitrided sample groups strongly hinder the access of the acid solution to the binder. Hence, the current densities measured were considerably lower in nitrided sample groups than in non-nitrided ones (Table 5, Fig. 5).

On the other hand, the enhanced resistance to corrosive media is associated with the high chemical stability of cubic refractory metal carbides, which is due to a maximum of filled bonding bands and a minimum of filled anti-bonding bands, hence their hardness is due to the strong covalency in these materials [54].

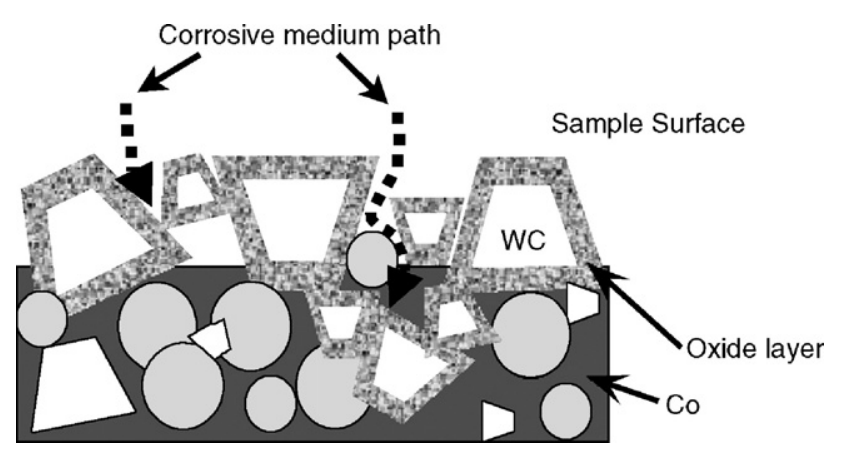

Fig. 16. Schematic of the structure of a corroded hardmetal after formation and deposition of the oxide layer around WC grains at the surface region and in the bulk restricting the path of the acid solution. 
The nitridation process improved the corrosion resistance of both the $\mathrm{Co}$ and the Ni-based hardmetals. In the Co-based samples the fcc-rich outer layer formed by the nitridation treatment is thicker compared to the Ni-based hardmetal. After corrosion the binder-depleted zone in the nitrided Co-based hardmetal extended deeper into the bulk than in the nitrided Ni-based hardmetal. This can be explained due to a larger amount of binder in the fccenriched near-surface zone of the Co-based hardmetal, which acts as path for the access of the corrosive medium to the binder in the bulk of the sample group.

In particular, nitridation of the Co-binder sample (B) gave rise to a change in shape of the potential-current density curve, in which no transition from a current density maximum to the pseudopassive region is observed. This behavior may be attributed to a mass transport controlled process, which is related to the fact that the Co binder phase in sample B is present at the surface as inclusions in the fcc-rich layer, therefore making it more difficult for the Co ions to reach the surface and form the path for further ions to diffuse towards the solution. This behavior also accounts for the noisy shape of the curve (Fig. 5a), in which the current density temporarily decreases followed by an abrupt increase as the ions from one of the Co inclusions are allowed to diffuse, this process acting as pitting-like corrosion.

Furthermore, at high corrosion potentials at which $\mathrm{W}$ is no longer stable, both the Co and the Ni-based nitrided sample groups show an increased corrosion resistance compared to the non-nitrided samples. This phenomenon can be explained by the formation of a chemically stable $(\mathrm{Ti}, \mathrm{Ta}, \mathrm{Nb})(\mathrm{C}, \mathrm{N})$ near-surface zone and also the reduction of the amount of binder phase, which represses the attack by the corrosive medium.

\section{Conclusions}

We investigated the electrochemical oxidation behavior of WC-TiC- $-(\mathrm{Ta}, \mathrm{Nb}) \mathrm{C}$ hardmetals with $\mathrm{Co}$ or $\mathrm{Ni}$ as the binder metal in $1 \mathrm{~N}$ sulphuric acid solution and the effect of a nitridation treatment. Morphological alterations that arise from differences in sample composition, the nitridation, and corrosive attack were characterized by means of optical and scanning electron microscopies. The main conclusions can be summarized as follows:

- The average grain size of the hard phases and the binder mean free path in the bulk are neither affected by the nitridation surface treatment nor by the composition of the binder.

- The surface layer microstructure (such as thickness and crystallite size distribution) is affected by the binder metal.

- The treatment under $\mathrm{N}_{2}$-containing atmospheres strongly increases corrosion resistance.

- Pseudopassivity is likely to be caused by diffusion restriction of the ions due to the hindered access of the corrosive medium to the inner binder.

\section{Acknowledgements}

Dr. A. Rothkirch, Dr. B. Hasse, and Dr. T. Wroblewski (HASYLAB@DESY, Hamburg, Germany) are kindly acknowl- edged for technical support during the diffraction experiments at the beamline G3. We would like to thank Dipl.-Ing. Claudia Juricic for her support during the X-ray measurements. This work was supported by the European Community, project Nr. I05- 035EC. One of the authors (F.S.) wishes to thank for financial support from the ADEMAT Network, Alfa Project Nr. II-0240-B1-AT-RT-CT.

\section{References}

[1] H.E. Exner, Int. Met. Rev. 243 (1979) 149.

[2] P. Ettmayer, Annu. Rev. Mater. Sci. 19 (1989) 145.

[3] E.J. Wentzel, C. Allen, Int. J. Refract. Met. Hard Mater. 15 (1997) 81.

[4] V.A. Pugsley, G. Korn, S. Luyckx, H.-G. Sockel, W. Heinrich, M. Wolf, H. Feld, R. Schulte, Int. J. Refract. Met. Hard Mater. 19 (2001) 311.

[5] J.A. Bailey, A study of the wear characteristics of cemented tugsten carbide cutting tools, Progress Reports I and II, Newman-Whitney Machine Company, Greensboro, NC, 1976.

[6] S. Sutthiruangwong, G. Mori, R. Kösters, Int. J. Refract. Met. Hard Mater 21 (2005) 129

[7] A.H. Human, H.E. Exner, Mater. Sci. Eng. A209 (1996) 180

[8] B. Roebuck, E.A. Almond, Mater. Sci. Eng. 66 (1984) 179.

[9] E.A. Almond, B. Roebuck, Mater. Sci. Eng. A105/106 (1988) 237.

[10] A.M. Human, B. Roebuck, H.E. Exner, Mater. Sci. Eng. A241 (1998) 202.

[11] S. Ekemar, L. Lindholm, T. Hartzell, Int. J. Refract. Met. Hard Mater. 1 (1982) 2144.

[12] W.J. Tomlinson, C.R. Linzell, J. Mater. Sci. 23 (1988) 914.

[13] A.M. Human, H.E. Exner, Int. J. Refract. Met. Hard Mater. 15 (1997) 65.

[14] S. Sutthiruangwong, G. Mori, Int. J. Refract. Met. Hard Mater. 21 (2003) 135.

[15] G. Mori, S. Sutthiruangwong, B. Schaffer, W. Grogger, R. Koersters, Proceedings PM2004, vol. 3, EPMA, Wien, 2004, p. 581.

[16] K.J.A. Brookes, World directory and handbook of hardmetals and hard materials, Ed. International Carbide Data (1998).

[17] A.M. Human, I.T. Northrop, S.B. Luyckx, M.N. James, J. Hard Mater. 2 (1991) 245

[18] W.J. Tomlinson, N.J. Ayerst, J. Mater. Sci. 24 (1989) 2348.

[19] D. Banerjee, G.K. Lal, G.S. Upadhyaya, J. Mater. Eng. Perform. 4 (1996) 563.

[20] German Patent No. 1243399 (1967).

[21] C. Xu, X. Ai, C. Huang, Int. J. Refract. Met. Hard Mater. 19 (2001) 159.

[22] L. Åkesson, PhD Thesis, Institutionen för Metallografi Kungliga Tekniska Högskolan, Stockholm (1982).

[23] J. Creus, H. Mazille, H. Idrissi, Surf. Coat. Technol. 130 (2000) 224

[24] O. Rüdiger, H. Grewe, J. Kolaska, Wear 48 (1978) 267.

[25] H. Suzuki, K. Hayashi, Y. Taniguchi, Trans. Jpn. Inst. Met. 22 (1981) 758.

[26] P. Ettmayer, H. Kolaska, W. Lengauer, K. Dreyer, Int. J. Refract. Met. Hard Mater. 13 (1995) 343.

[27] M. Ekroth, R. Frykholm, R. Lindholm, H.-O.- Andrén, J. Ågren, Acta Mater. 48 (2000) 2177.

[28] J. Zackrisson, U. Rolander, B. Jansson, H.-O. Andrén, Acta Mater. 48 (2000) 4281 .

[29] A. Doi, T. Nomura, M. Tobioka, K. Takahashi, A. Hara, Proc. 11th Plansee Seminar, vol. HM8, 1985, p. 825.

[30] H.-O. Andrén, Mater. Chem. Phys. 67 (2001) 209.

[31] J. Garcia, PhD Thesis, Technische Universität Wien, 590605II (2001).

[32] I.Y. Konyashin, Surf. Coat. Technol. 73 (1995) 125.

[33] L. Chen, W. Lengauer, K. Dreyer, Int. J. Refract. Met. Hard Mater. 18 (2000) 135 .

[34] K. Tsuda, A. Ikegaya, K. Isobe, N. Kitagawa, T. Nomura, Proc. EURO PM'1996, 1996, p. 45.

[35] K. Dreyer, D. Kassel, H.-W. Daub, H. van den Berg, W. Lengauer, J. Garcia, V. Ucakar, Proc. 15th Plansee Seminar, vol. 2, 2001, p. 817.

[36] W.E. Hillis, Wood extracts and their significance to the pulp and paper industry, Academic Press, New York, 1962.

[37] W.M. Mackenzie, W.E. Willis, Wear 8 (1965) 238. 
[38] J.A. Bailey, A.-M. Bayoumi, J.S. Stewart, Wear 85 (1983) 69.

[39] K. Van Acker, L. De Buyser, J.P. Celis, P. Van Houtte, J. Appl. Crystallogr. 27 (1994) 56.

[40] H.G. Prengel, W. Heinrich, G. Roder, K.H. Wendt, Surf. Coat. Technol. 68/ 69 (1994) 217.

[41] G.E. D’Errico, R. Chiara, E. Guglielmi, Surf. Coat. Technol. 86/87 (1996) 735.

[42] H.G. Prengel, P.C. Jindal, K.H. Wendt, A.T. Santhanam, P.L. Hedge, R.M. Penich, Surf. Coat. Technol. 139 (2001) 25.

[43] J. Tafel, Z. Phys. Chem. 50 (1905) 641.

[44] B. Bozzini, G.P. De Gaudenzi, A. Fanigliulo, C. Mele, Mater. Corros. 54 (2003) 295.

[45] E. Cazzanelli, G. Mariotto, C. Vinegoni, A. Kuzmin, J. Purans, Ionics 5 (1999) 335.

[46] B. Bozzini, G.P. Gaudenzi, A. Fanigliulo, C. Mele, Corros. Sci. 46 (2004) 453.
[47] B. Bozzini, G.P. Gaudenzi, M. Serra, A. Fanigliulo, F. Bogani, Mater. Corros. 53 (2002) 328

[48] C. Edtmaier, R. Schiesser, C. Meissl, W.D. Schubert, A. Bock, A. Schoen, B. Zeiler, Hydrometallurgy 76 (2005) 63.

[49] D. zur Megede, E. Heitz, Mater. Corros. 37 (1986) 207.

[50] M. Pourbaix, Atlas of Electrochemical Equilibria in Aqueous Solutions 2nd edition, NACE, 1974.

[51] P. Schmuki, J. Solid State Electrochem. 6 (2002) 145.

[52] E. Kny, L. Schmid, Int. J. Refr. Met. Hard Mater. 6 (1987) 145.

[53] G. Mori, H. Zitter, A. Lackner, M. Schretter, in: G. Kneringer, H. Wildner (Eds.), Proc. 15th Plansee Holding Seminar, Plansee Holding Ag, vol. 2, 2001, p. 222, Reutte.

[54] R. Freer, The Physics and Chemistry of Carbides, Nitrides and Borides, Kluwer, Dordrech, 1990. 